\title{
효과적인 SDGs 이행을 위한 KOICA 중장기 전략 수립 논의 \\ :KOICA 교육전략(2016-20)(안)
}

\section{목 차}

I. 들어가면서

II. KOICA 교육 전략(2016-2020)

III. 한국 교육 분야 개발협력 추진의 주요 쟁점

1. SDGs 교육목표에 관한 비판적 검토

2. KOICA 중장기 전략방안에 대한 논의

IV. 나가면서

\section{I. 들어가면서}

2015년 이후 전 지구적 교육개발협력 의제는 '모든 이들을 위한 포용적이고 평등한 양질의 교육 보 장 및 평생학습기회의 보장’으로 요약된다. UNESCO와 UNICEF, World Bank를 포함하는 교육개발 관련 기구들이 중심이 되었던 세계교육포럼(World Education Forum, WEF)은 '모든 이를 위한 교육 (Education for All, EFA)'의 향후 과제는 UN에서 지난 9월 공표한 '지속가능발전목표(Sustainable Development Goals, SDGs)'의 교육 분야 목표와 일치된 것으로 결정되었다(UN 2015). 7개의 목 표와 3 개의 추진 전략을 포함한 교육 분야 행동강령은 11 월 $\mathrm{UNESCO}$ 총회에서 최종 확정되었다 (UNESCO 2015b). MDGs의 8개 목표보다 훨씬 많은 17 개의 목표와 169 개의 타겟을 제시한 SDGs는 2030년까지 효과적인 교육개발협력을 위한 논의의 토대가 될 것이다.

1) 서울대학교 교육학과 교수

2) $\mathrm{KOICA}$ 교육보건팀 전문관 
교육개발협력 의제로 제시된 구체적인 내용은, ' $\triangle$ 기초교육(초 · 중등교육) $\triangle$ 영유아 보육·교육 $\triangle$ 직능 · 중등교육 이후의 교육(고등교육 · 평생교육) $\triangle$ 직업을 위한 기술 $\triangle$ 성차별 제거 및 취약계층 보 포 $\triangle$ 문해 및 기초 수리력 보장 $\triangle$ 지속가능발전을 위한 지식과 기술 획득'과 실행목표로 ' $\triangle$ 교육시설 및 학습 환경 제공 $\triangle$ 장학금 수 확대 $\triangle$ 양질의 교원 공급 확대'를 포함하고 있다. 거의 대부분의 개발 목표들이 1990년 좀티엔 회의에서 $\mathrm{EFA}$ 의 최초 의제로 제시되었던 것에서 크게 달라지지 않았다. 그 러나 2000년 다카르 회의를 거치면서 교육개발의제는 전 영역을 아우르는 광범위한 내용을 담지하게 되었다. 영유아 교육부터 고등교육, 그리고 청소년-성인교육에 이르기까지 전 생애에 걸친 교육/학습 을 포함하고 있다. 또한 MDGs에서 양적인 기회의 확대에 강한 관심을 보였었다면, SDGs에서는 양 적인 기회의 부여는 물론 교육의 질적 측면을 강조하고 있다. 학습 성과라든지, 기술개발 그리고 학습 환경개선 및 교사교육에 관심을 기울이는 이유가 여기에 있다.

이로서 1948년 세계인권선언에 담겨있는 '인권으로의 교육'은 이제 수사적인 차원을 넘어 본격적인 실행차원의 목표로 제시되었고, 향후 15 년 동안 이에 대한 모니터링 및 평가가 이루어질 것으로 보인 다. 2016년도에 발표될 평가와 모니터링을 위한 목표별 구체적인 지표가 아직 작업 중에 있기는 하지 만, 복잡한 교육 분야의 목표를 설정하고, 이를 실현하기 위한 전 지구적 노력의 중요한 틀에 대한 사 려 깊은 논의들이 이어지고 있다.

국내의 국제개발협력 담론의 플랫폼으로서 이번 제 29 회 국제개발협력포럼은 중요한 계기라고 할 수 있다. 즉, $\mathrm{KOICA}$ 에서 향후 5년 동안 중기 전략을 통하여 SDGs에서 제시한 교육목표를 이행하기 위한 청사진을 제시하고, 논의할 수 있는 자리를 마련하였다는데 큰 의미가 있다. 한국의 무상원조를 담당하고 있다는 사실을 넘어, 한국이 국제사회의 공통적 개발목표를 어떻게 이해하고, 보다 구체적 인 실천방안을 마련하기 위한 선도적인 역할의 전략의 논의거리를 제공하고 있기 때문이다. 무엇보다 $\mathrm{SDGs}$ 의 4 번째 목표였던 교육 분야 개발협력의 각 세부목표들이 한국사회에서 보다 진지하게 논의될 수 있도록 다양한 쟁점들이 제공되고, 비판적으로 검토되어야 할 필요가 있다.

본 연구는 이러한 맥락에 따라 향후 교육 분야 개발협력의제에 관한 논의거리를 위한 토대로 문제 를 제기하고, 생산적인 논의토대를 제공하는데 목적을 둔다. 본고의 내용은 크게 두 가지로 구분하여 제시될 것이다. 하나는 KOICA에서 마련한 교육 분야 개발협력의 중기 발전전략(안)을 소개하는 것이 고, 다른 하나는 이를 매개로 교육 분야 개발협력의 의미를 분석하고 향후 전망과 전략을 제시하는 것 이다. 후자의 경우 두 가지 방향에 있어 논의를 전개할 것이다. 우선, SDGs의 교육목표에 관한 것이 며, 다른 하나는 $\mathrm{KOICA}$ 중기전략에 관한 것이다. 특히 $\mathrm{KOICA}$ 의 중기 추진 전략을 어떻게 수정할 것 인가라는 질문에 답변하기 보다는 이를 실행하는 차원에서 관심을 가져야 할 부분에 관한 내용에 집 중할 것이다. 이를 토대로 구체적인 방안 및 실행전략에 대해서는 지속적으로 대화할 수 있을 것이라 고 생각한다. 


\section{KOICA 교육 전략(2016-2020)}

국제사회는 2000-2015 기간 동안 '보편적 초등교육의 달성'이라는 MDGs 두 번째 목표를 달성기 위하여 지난 15 년간 초등학교 등록률 제고를 위해 교육 분야 지원을 집중해왔다. 그 결과 전 세계 평 균 초등학교 순 취학률(net enrollment ratio)은 2000년 83\%에서 2012년 90\%로 크게 증가되었고, 그 결과 학교 밖 아동 수는 2000년 1억 명에서 2012년 5,800만 명 수준으로 줄어들었다(UNESCO 2015a).

그럼에도 불구하고 최근 학교 밖 아동 수 감소 속도가 늦춰지고 있으며, 이들 대부분이 분쟁지역의 아동들이라는 사실은 교육의 형평성 측면에 더 많은 국제사회의 관심과 지원이 필요하다는 점을 드러 내고 있다. 초등학교에 입학한 개발도상국 아동 중 4 분의 1 은 중도 탈락 할 가능성이 높으며, 기초적 문해 능력(읽기, 쓰기, 셈하기 능력)을 가지고 있지 못한 전 세계 7,800 만 명의 성인과 1 억 2,600 만 명의 청소년 중 $60 \%$ 이상이 여성이라는 사실은 이를 증명하는 것이다.

KOICA는 SDGs 교육 목표별 분석에 따라 향후 2030년까지 KOICA의 대응방안에 대한 방향성을 이미 정립한 바 있다(장은정 외 2015). KOICA는 제29회 국제개발협력포럼을 계기로 2016-2020 기 간 추진할 $\mathrm{KOICA}$ 교육 전략 초안을 국내 교육 전문가 및 다양한 이해관계자와 공유하고 SDGs의 첫 번째 5 개년을 이끌어 갈 기관의 방향성을 정립하고자 한다.

SDGs 시대를 맞아 국내적으로도 제2차 국제개발협력 기본계획 및 2기 국가협력전략(CPS) 수립되 고 있는 바, $\mathrm{KOICA}$ 는 국가 차원 차기 ODA 전략 수립에 따른 $\mathrm{KOICA}$ 교육 분야 사업 추진전략 및 국 가별 교육 프로그램 수립방향 연계하여 차기 교육 전략을 수립해가고자 한다. 또한 교육 ODA 사업의 효과성 및 지속가능성 강화를 위하여 새로이 등장하는 다양한 개발협력 이해관계자와의 파트너십을 제고하고, 프로젝트 위주 성과관리에서 탈피하여 전략목표 중심 다양한 사업형태별 핵심 성과지표 풀 (pool)을 중심으로 한 통합적 성과관리를 지향하고자 한다.

$\mathrm{KOICA}$ 는 지난 포럼에서 학습 성과를 위한 양질의 교육, 안전하고 건강한 학교, 취약계층을 위한 포용적 교육, 미래를 위한 기술역량 강화, 개발을 위한 지식허브 구축 등 다섯 가지 세부목표〈그림 1 참조>를 제시하고 학계와 시민사회를 포함한 다양한 이해관계자의 검토의견을 수렴하였다. 특히 포럼 에서 제시된 전략(안)은 2015년 3월부터 8개월여 간에 걸쳐 $\mathrm{KOICA}$ 와 시민사회가 테스크포스를 구

3) KOICA-시민사회 TF는 KOICA의 제안으로 국내 시민사회 대표기관인 국제개발협력시민사회포럼(KoFID) 교육개발 협력분과 내에서 자체 선정한 시민사회 기관와의 협력을 통해 구성함. 
〈그림 1〉 KOICA 교육 전략 (2016-2020) 초안

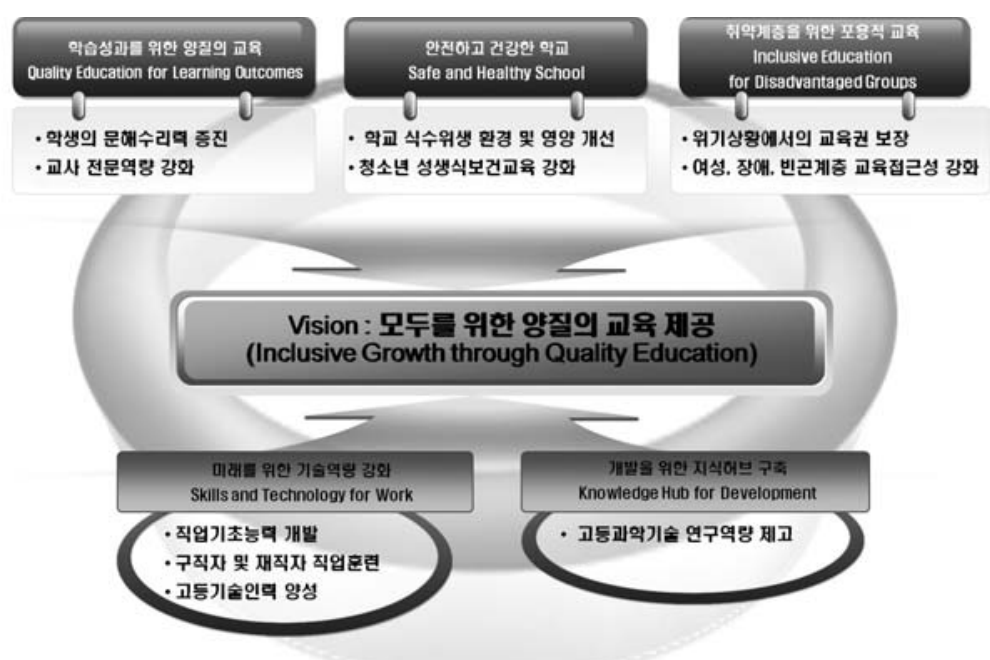

출처: 제29회 개발협력포럼 교육 세션 발표자료

성하여 발간한 '2016-2020년 기초 및 취약계층 교육지원 공동제안서'를 통해 특히 기초교육과 취약 계층 대상 교육지원에 대한 공동논의에 기반을 두어 수립된 것이다.

$\mathrm{KOICA}$ 는 포럼을 통해 각 세부목표(안)의 주요 내용과 성과지표 pool을 공유하고, 더불어 지난 UN 개발정상회의에서 대통령이 발표한 '소녀들의 보다 나은 삶(Better Life for Girls)' 구상의 구체 내용 및 파트너십 방안에 대한 KOICA의 계획을 발표하였다. ${ }^{4)}$

\section{III. 한국 교육 분야 개발협력 추진의 주요 쟁점}

\section{SDGs 교육목표에 관한 비판적 검토}

지속가능발전(SD)은 다섯 가지의 가치에 토대하고 있다. 5PS(People, Planet, Peace, Prosperity, Partnership)로 상징되는 것들로, '사람,' '지구,' ‘평화, '번영' 그리고 '협력'이다. 이를 상

4) 자세한 내용은 KOICA 홈페이지 'ODA알기’에 게시된 제29회 포럼 발표자료 및 동영상 참조. 
기해 보면, 향후 전 지구적 발전의 근본적인 토대가 다른 무엇보다도 '교육'일 수밖에 없다는 점을 인 식하게 된다. 교육은 단지 학교교육으로 표상되는 제도를 넘어서는 것으로, 인간 삶의 근본적인 토대 라고 할 수 있다. 교육은 '교육적 관계'를 통하여 사람과 사람, 사람과 제도, 사람과 환경, 사람과 공동 체, 사람과 자본을 이어주는 것으로, 이것이 결핍된 상태에서는 그 어떤 사회적 진보나 발전도 가능하 지 않다(Rogers 1995). 교육은 인간과 지구, 그리고 인간과 인간을 매개하고 발전적 상호작용관계를 가능하게 해주는 필수불가결한 활동이다.

실제 SDGs의 17 개 전략을 교육을 중심으로 성찰하고, 이를 실현하기 위한 중장기 전략-목표에서 교육의 필수불가결함을 인식하고 있다는 점이 충분히 드러나 있는지를 모르겠다. 그러나 교육 분야의 7 개 목표들을 살펴보면서, 교육이 단지 인간의 제도화된 형식교육 안에서만 이루어지는 것이 아니라 는 점을 강조하고 있다. '평생 학습’이라는 용어가 단지 전 생애를 지칭하는 것이 아니라, 한 개인의 삶 을 중심에 두고 일어나는 형식, 무형식, 비형식 학습 전반을 개발(development)의 구성 요소로 인식 하고 있음을 의미한다. 이 점에 있어, 어쩌면 SDGs의 다른 목표들과의 관련에 대해서 살펴볼 때, 교 육적 관계와 교육적 개발의 관점을 적용해 볼 수 있는 여지가 향후 커지리라 기대해 볼 수 있다.

그러나 SDGs의 교육 분야 개발협력 목표가 보이는 특징을 비판적으로 살펴볼 필요가 있다. 다음 과 같이 SDGs의 교육목표에서 볼 수 있는 특징들을 기술해 볼 수 있다.

우선 제안할 수 있는 거의 모든 교육목표들을 다 포괄하고 있다. 앞서 언급한 것과 같이 SDGs의 교육목표는 영유아 교육부터 고등교육 및 성인교육까지 포괄하고 있다. 접근성 확대라는 양적 목표 에서부터 학습 이후 구체적인 성과까지 측정하고 관리하겠다는 질적 목표까지 아우르고 있다. 제도 안팎의 교육적 관계를 포괄적인 발전의 대상으로 포섭하고 있다는 점, 그리고 형식적 교육체제를 넘 어 $\mathrm{ESD}, \mathrm{GCED}$, 평화교육, 국제이해교육 등 비가시적인 무형식학습(informal learning)까지 담고 있다.

교육의 성과는 단지 접근성에 의한 기회부여를 넘어서서 개인의 삶의 질을 스스로 개발해 나갈 수 있도록 해주는 것이어야 한다는 점에서 구체적인 직업세계로 연계할 수 있는 경로를 구체화하고자 한 다. 즉, 학교교육에서의 일반교육과 연계하여 직업기술교육/훈련은 직업연계의 가능성, 취업에 필요 한 아주 구체적인 기술의 습득 유무로 판단되어야 한다는 점을 강조하고 있다. 이점에 있어 향후 교육 의제들이 교육의 질을 특히 강조되고 있다는 점을 주목할 필요가 있다.

이는 그리 새로울 것은 아니지만, 이전과 달리 양질의 교육을 조작적으로 정의하고 이를 실현하 기 위한 구체적인 실행전략을 채택하고 있다는 점에서 특징을 갖고 있다. 즉, 학습 성과(academic performance) 측정 및 비교, 교사교육 및 훈련을 강조하여 교사들의 교수학습역량 강화, 구체적인 교육재정 확보 및 투입 강조 등이 이를 뒷받침하고 있다. 또한 가능한 모든 취약계층을 아우르기 위한 
방안을 강구한다는 점에서 상당히 진보적인 목표를 담고 있다고 보인다. 여성, 장애자, 원주민, 난민/ 이민자 등 기존의 개발목표에서 별도로 다루어졌던 사회, 정치, 경제, 문화적 공동체를 적극 포함하고 있기 때문이다.

그러나 이러한 특징 때문에 SDGs 교육목표가 갖는 한계 또한 분명해 보인다. 이를 몇 가지로 정리 해 볼 수 있을 것이다.

- 하나. 목표로 설정할 수 있는 모든 것이 포함되어 있다고 한다면, 정작 어느 것을 우선적인 과 제로 선택하여 구체적으로 실현할 것인가에 대해서 별로 전달해 줄 수 있는 정보가 없다고 봐 야한다.

- 둘. 지나치게 교육의 성과를 직업세계와 연계하다보면, 직업세계가 교육, 특히 제도화된 교육세 계의 정책에 과도한 개입이 이루어질 수 있다.

- 셋. 학습 성과 또한 구체적인 평가 결과를 의미하는 것으로 단순화되거나, 가시적인 시험 결과로 표상되는 것을 의미한다면 교육본연의 교수-학습의 의미가 급속도록 퇴색될 수 있을 것이다.

- 넷, 성과로 측정하기 어려운 주제들, 즉 $\mathrm{GCED}, \mathrm{ESD}, \mathrm{EIU}$ 등의 활동과 취약계층 대상의 교육활 동은 다른 과제들에 비해 관심 밖에 머무를 수밖에 없으며, 곧 현 상황의 변화에 영향을 끼치기 어려울 것이다.

이러한 맥락에서 $\mathrm{KOICA}$ 의 중기전략이 한국의 개발협력, 특히 교육 분야 개발협력에서 어떻게 이 행/실현될 수 있는지 의미를 검토해보고 조망해보는 것은 의미심장하다.

\section{2. $\mathrm{KOICA}$ 중장기 전략방안에 대한 논의}

$\mathrm{SDGS}$ 시대를 준비하는 한국의 국제개발협력에서 $\mathrm{KOICA}$ 중장기 전략은 그 의미가 크다. 교육 분 야의 경우 2011-2015년까지의 이전 전략에서 진일보한 가치와 사업영역을 제시하고, 보다 효과적인 방안을 제시한 것으로 보인다. 그러나 본 논의가 SDGs의 교육 분야 목표들을 어떻게 이해하고 있고, 이행을 위한 전략 및 가치들을 어떻게 설정하고 있으며, 또한 보다 실행 가능한 사업의 내용들을 어떻 게 그려내고 있는지에 관하여 질문 형식의 이슈를 아래와 같이 제기하고자 한다.

\section{1) 본 전략은 SDGs에 대해 어떻게 이해하고 있는가?}

- 7가지 목표 중 영유아 교육이 포함되어 있지 않고, $\mathrm{ESD} / \mathrm{GCED}$ 를 적극적으로 프로그램화하지 않고 있다. 지난 MDGs에서 조차 강조되지 않고, 큰 진전이 없었던 영유아 교육에 대해 강조하 지 않은 이유가 궁금하다. 전략안에 따르면 다양한 사각지대의 취약계층을 포함하는 것을 염두 
에 두고 사업을 형성, 추진할 의지를 보였음에도 굳이 영유아 교육이 제외된 근거가 무엇일지 궁금하다.

- 제도로서의 초중등교육, 과학기술연구역량 강화를 위한 고등교육, 직업연계 기술교육훈련을 강 조하고 있다. 지난 15 년 동안의 교육 분야 개발협력 성과로 높은 취학률과 취학 기회 확대를 위 한 학교환경의 개선이 있었던 것은 분명하다. 그럼에도 불구하고, 여전히 제도 속에서의 형식교 육에의 접근성 강화와 질 높은 교육학습 환경 구축, 그리고 학습 성과를 바탕으로 한 교육목표 실현을 연계하고 있다.

- '질 높은 교육'에 대한 $\mathrm{KOICA}$ 의 해석은 교사역량, 인프라 개선, 학습 성과, 구체적인 직업기술 습득 등으로 이루어지고 있다. 만약 $\mathrm{KOICA}$ 의 이해가 이전 MDGs에서의 교육목표와 차별성을 갖고 있다는 전제를 한다면, 이번 전략은 '양질의 교육'에 대해 진지한 고민이 담겨있어야 한다. 아직 구체적인 내용이라고 할 만한 실행수준의 방안이 아니어서 이에 관한 논의를 깊이 할 수 없지만, 향후 이에 대한 고민의 결과를 보여주기를 기대한다.

\section{2) 본 전략은 SDGs 이행을 위한 어떤 가치에 입각해 있는가?}

- 중기 전략은 지속가능성, 인권으로서의 교육, 포용성, 전문성 등의 가치들을 표방하고 있고, 사 업성과 관리측면에서 효율성/효과성을 강조하고 있다. 즉, $\mathrm{KOICA}$ 는 교육 분야의 목표 달성이 라는 전 지구적 요구에 있어 국제사회의 개발협력 규범에 따르고 있는 것으로 보인다.

- '건강'하고 '행복'한 학교를 상징적으로 내세운 전략의 내용은 교육 분야의 중요한 가치를 잘 내 포한 것으로 보인다. 전체 세부 목표를 아우르는 목표가 '모두를 위한 포용적이고 질 높은 교육 과 평생학습 제공'이라는 목표를 잘 인식하고 있다.

\section{3) 본 전략은 SDGs 이행을 위해 어떤 내용을 담고 있는가?}

- KOICA는 국제사회의 원조효과성을 따르는 양자협력 기관이다. 따라서 DAC/OECD에서 제시 하고 있는 포괄적인 성과 관리 체제를 마련하고, 보다 효과적인 개발협력사업의 추진과 평가가 강조될 수밖에 없다. 아직 확정되지는 않았지만, 양질의 교육을 위한 두 층위의 교육사업 내용 은 이러한 $\mathrm{KOICA}$ 의 성과관리 체제에서 어떻게 구현될 수 있을 것인지 궁금하지 않을 수 없다.

- 특히 (1) 학습 성과 기반 교육의 질 강조, (2) 산업수요기반 직업훈련 강조, (3) 과학기술분야의 고등교육지원을 강조하고 있는 SDGs의 교육목표들은 어떠한 지표를 구체적인 성과로 인지하 고, 실현할 것인지 제시할 수 있어야 한다. 그 어느 때보다도 SDGs에서의 교육목표는 성과지표 를 둘러싼 논쟁이 뜨겁다. 이는 MDGs에서의 지표가 양적 성장과 표면적인 개발의 측면을 측정 
한 것에 대해 강한 반발이 있었고, 이러한 문제의식에 따라 SDGs에서는 비가시적이고 의식적 이고 정서적인 발달의 측면을 내포하고 있기 때문이다.

- 이러한 점에서 '안전하고 건강한 학교'와 '취약계층을 위한 포용적 교육'이라는 두 가지 전략적 실행목표가 제시되어 있다는 점은 기존의 성과관리에 강조를 두던 $\mathrm{KOICA}$ 에서 교육의 질 문제 를 구체적으로 어떻게 접근할 것인가에 관해 관심을 갖게 하는 대목이다. 물론 취약계층에 대한 명확한 개념을 제시하지는 않았지만, 교육의 질 문제를 단지 학습 성과의 탁월성만을 의미하는 것이 아니라, 사회계층의 불평등과 격차 문제까지 포괄적으로 다루겠다는 의미를 담고 있기 때 문이다. 과연 이후의 구체적인 실천 내용은 무엇이 될 것인가?

\section{4) 'Better Life for Girls' 추진 전략에 관한 쟁점}

한국은 2015년 10월에 열린 UN 개발정상회의에서 개발도상국의 여아 및 여성청소년을 대상으로 총 2 억 달러를 지원하겠다고 약속했다. 지원 내용은 교육과 보건 분야, 그리고 구체적인 직업기술을 익히도록 하여 소득창출과 함께 공동체의 리더쉽을 가질 수 있도록 미래지향적인 사업으로 삼겠다는 의도이다. 이 사업의 구체적인 내용이 나오지 않은 상황이지만, 전 세계 15 개국(아시아 6 개국, 아프리 카 6 개국, 중동 1 국가, 중남미 2 개국 + 기타)을 대상으로 한 여아들의 양질의 삶을 지원하겠다는 점에 서 호평을 받고 있다.

그러나 여아 및 여성청소년을 위한 국제사회의 의제설정과 구체적인 사업재원 확보라는 것이 굳이 새로울 것은 없다. MDGs의 세 번째 목표와 SDGs의 다섯 번째 목표에서 다양한 사회문화적인 측면 에서의 성 평등을 개발의 목표로 제시한 만큼, 전 지구적인 성 차별, 성별 격차의 문제는 심각한 개발 의 과제였다. 이러한 맥락에 따라, 국제사회와의 이번 약속은 적어도 개발협력의 큰 틀에서 성평등의 문제에 단지 수사적인 차원을 넘어 보다 적극적으로 대응하겠다는 실천으로 받아들일 수 있다.

'Better Life for Girls' 의제(initiative)의 구체적인 실행방안을 제시하지 않고 있는 상황에서 이에 대한 쟁점을 제시하는 것의 의미는 하나이다. 구체적인 실행방안에 적어도 아래 이야기하는 내용이 반영되어야 한다는 점 말이다. 이에 다음과 같은 쟁점을 제시하고자 한다.

- 여아의 교육은 사회문화적으로 민감한 사안일 수밖에 없다. 국제사회에서 주요한 개발 목표로 설정하였다고 해서, 어느 곳에서나 원하는 프로그램을 그대로 실행할 수는 없다. 즉, 개도국의 실제 개인들의 삶 속에서 '여성 됨'의 의미와 '여아로 살아가기'의 실제를 인식하고, 이해하고, 이에 적절하게 관여할 수 있는 매개를 어떻게 마련할 수 있을지 고민해야 한다.

- 이러한 점에서 성공적인 '여아교육/보건'의 사례가 있을지는 모르겠지만, 그 사례가 바로 확산될 수 있는 또 다른 모범적인 사례가 되기 어렵다. 즉, 사례와 사례 간의 성과와 의미를 서로 공유 
하고 여아 교육의 성과를 공유할 수 있는 플랫폼이 마련되어야 한다.

- '여아들의 삶'을 둘러싼 차별과 문제는 단일하지 않다. 복합적이고 다층적인 사회문화적인 요인 과 계급적/경제적인 모순이 공히 작동하고 있다. 따라서 비록 교육과 보건을 대표적인 실행 프 로그램 영역으로 제시하고 있지만, 교육과 보건 프로그램은 보다 문화적인 성격을 지닌 프로그 램으로 기획되어야 한다.

- 한국은 이러한 점에 있어서 아직 배워야 할 전문적인 것들이 많다. 예를 들어, 어느 지역의 성 인지 제고 및 성차별 극복을 위한 사례들이 보고되고 있는지, 특정 지역의 여아 교육/보건 사업 에 있어 성공적인 요인들은 무엇이었는지, 국제사회에서 여아/여성의 빈곤, 건강, 교육문제를 통한 사회변화에 기여하고 있는 기관, 기구, 단체들은 어떤 것들이 있는지에 관한 것들이 그것 이다. 이를 위해 과연 우리나라의 지역전문가들과 젠더 전문가들이 충분한지부터 질문하는 것 이 옳다.

- 지나치게 성과에 집착하지 않는 사업내용으로 구성되었으면 한다. 이는 여성의 차별이 단지 경 제적인 빈곤의 문제가 아니라면, 당장의 개입과 지원으로 대단한 성과를 보이기 어렵기 때문이 다. 따라서 보다 중장기적인 지원전략을 세우고, 지속적인 관심을 기울이며 성과를 모니터링 할 수 있는 체제를 마련해야 할 것이다.

\section{IV. 나가면서}

일반적으로 성과관리를 강조하고 있는 만큼 $\mathrm{KOICA}$ 가 지원하는 사업(프로그램, 프로젝트)의 성과 를 측정할 수 있는 지표 중심으로 목표가 적절하게 제시되었다고 보인다. 특별히 SDGs의 학교교육이 '안전하고 건강한 교육'을 제공해야 한다고 함으로써 교육의 질에 대해 상당히 포괄적인 방식으로 규 정하고, 접근한다는 점에서 인상적이라고 보인다. 또한 'Better Life for Girls' 추진전략의 경우, 한국 이 전 세계적인 성차별 문제에 보다 큰 관심과 함께 문제를 해결하는데 적극적으로 참여하겠다는 의 지로 읽히는 만큼, 재원의 추가확보까지 고려하여 본 전략의 이행이 잘 이루어지기 바란다.

$\mathrm{SDGS}$ 에 조응하는 $\mathrm{KOICA}$ 의 교육 분야 중기 전략(안)의 내용에 관한 논의를 토대로 다음과 같은 질문 및 제언을 덧붙이고자 한다.

우선 지금까지 KOICA가 추진해 온 교육사업에서 기초교육-직업교육훈련-고등교육의 비중이 큰 변화 없이 유지되어 왔다. 아마 이러한 기조에서 향후 5 년의 중기전략에서 동일한 영역에 대한 사업 들이 제시되었을 것으로 파악된다. 그렇다면 지금 제시한 중기전략과 이전의 중기전략(2010-2015) 
과의 차이가 어떠할지 생각해본다. 그러나 (솔직히) 본 중기전략이 내세운 의미 있는 개념들이 어떻게 차별화된 사업(프로그램, 프로젝트)로 자리매김할지 감이 잡히지 않는다. 여전히 Scholarship Aid, $\mathrm{WFK}$ 의 비중이 줄어들지 않고, 직업기술교육훈련이 훈련원 건립, 기자재 제공 및 훈련원 운영에 집중 하는 것이라면 사실 기존 전략과 큰 차이를 발견하기 어렵다고 판단된다.

둘째, $\mathrm{KOICA}$ 의 지금까지 교육 분야 성과가 어떻게 축적되어 왔는지 질문하고 싶다. 성과라는 것 은 어떤 결과보고가 있었고, 이들이 양적 누계가 어떠하나는 것만을 의미하는 것이 아니라, 실제 사업 을 수행하고 사업의 공과에 대해 실행차원의 경험, 노하우, 인적자원의 전문성이 어떠한 방식으로 활 용되고 있는지를 포함하는 것이다. 교육 분야 있어 단순히 재원을 지원하는 것에 그치지 않는다면 교 육 분야의 성공적인 사례와 이유, 이를 하나의 중요한 모델로 구안하고 확산하려는 노력이 보다 다각 적으로 제시될 수 있었으면 좋겠다. 비록 $\mathrm{MDGs}$ 에 보다 적극적으로 대응하지 못하였다고 하더라도 $\mathrm{SDGS}$ 의 목표를 이행하는데 있어서는 이러한 $\mathrm{KOICA}$ 의 프로그램 운영의 경험과 모델의 축적 및 확산 보고가 많아지기를 기대해 본다.

셋째, 특히 'Better Life for Girls' 전략을 위한 사업형성 및 성과 있는 사업운영을 위한 구체적인 프로그램들이 어떠할지 제시되었으면 좋겠다.

넷째, 어떤 일을 어떻게 하겠다는 구상에서 흠을 잡는 것이 쉽지 않다. 그러나 당장 이를 추진하 겠다고 발을 떼는 순간 청사진에서 제시한 것에 비추어 사업의 내용, 형식, 방법, 참여방식 및 모니 터링 등이 어떻게 유기적으로 연계되어, 의도한 성과로 이어질 수 있는지 끊임없이 질문할 수밖에 없다. 이는 사업의 형성과정에서 '어떤 사업'을 결정할 것인가라는 문제 있어 핵심적인 문제일 수밖 에 없다. 한 가지 제언을 하자면, 사업의 최종 성과를 상당히 융통성 있게 잡는다면, 세 가지 이행목 표와 두 가지 추진목표를 보다 포괄적이고 개방적인 목표로 이해하고 사업을 형성할 수 있도록 하는 것이 필요하다.

이에 덧붙여 여전히 교육 분야 사업에 있어서 실제 추진과정에서 우선순위의 정치적 역학이 어떻 게 작동할 것인지 염려가 된다. 무엇보다도 기초교육에 대한 지원이 줄지 않기를 바란다. 또한 성과 를 모니터링하고 평가하기 위한 플랫폼의 변화가 있을 것인지 질문하지 않을 수 없다. 이런 점에서 $\mathrm{SDGs}$ 시대의 교육 분야 성과평가에 대한 고민이 함께 이루어지기를 바란다.

※ 참고: KOICA 교육 전략(2016-2020)은 제 29회 개발협력포럼 이후 지속적인 대내외 검토결과 및 제언을 수용하여 수정 후 2016년 확정 공표할 예정임. 


\section{〈참고문헌〉}

장은정 외. 2015. "Goal 4 모두를 위한 포용적이고 공평한 양질의 교육 보장 및 평생학습 기 회 증진”. 한국국제협력단 편. 『지속가능개발목표(SDGs) 수립현황과 대응방안』. 한국국제 협력단

굿네이버스, 글로벌발전연구원(ReDI), 세이브더칠드런, 월드비전, 한국국제협력단. 2015. “2016-2020년 기초 및 취약계층 교육지원 공동제안서(발간예정)”. KOICA-시민사회 공 동제안서 테스크포스

UN. 2015. "Transforming Our World: The 2030 Agenda for Sustainable Development(A/RES/70/1)". UN

UNESCO. 2015a. "EFA Global Monitoring Report. Education for All 2000-2015: Achievements and Challenges". UNESCO

UNESCO. 2015b. "Education 2030 Incheon Declaration and Framework for Action: Towards inclusive and equitable quality education and lifelong learning for all”. UNESCO 